Supporting Information

\title{
Simultaneous Bottlebrush Polymerization
}

\author{
Katharina E.I. Kluthe, Manfred Wagner, Markus Klapper ${ }^{\star}$ \\ Max Planck Institute for Polymer Research, Ackermannweg 10, 55128 Mainz,
}

Germany 


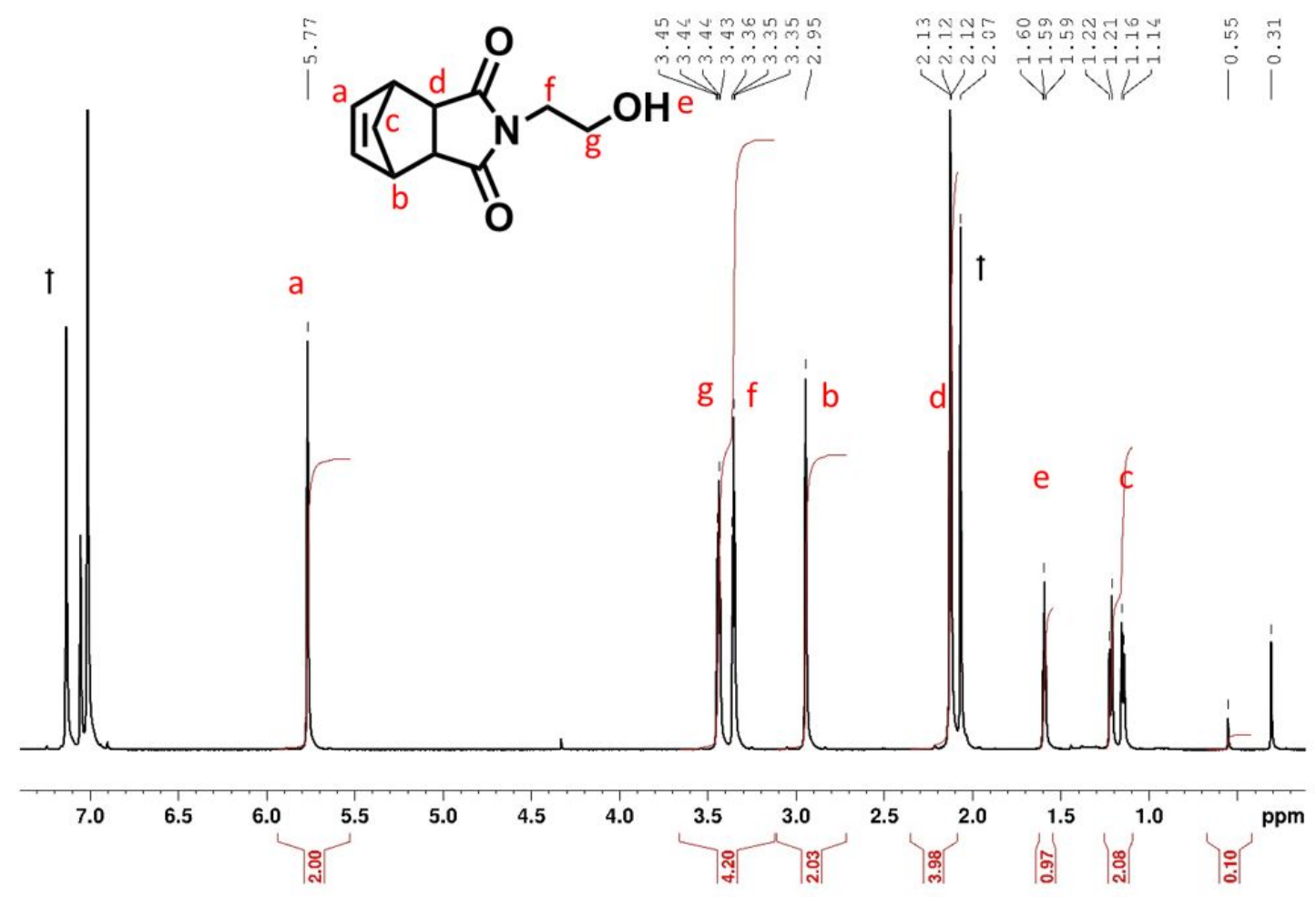

Figure S1. 1H NMR spectrum of HONDC monomer in toluene-d8 at $298 \mathrm{~K}$

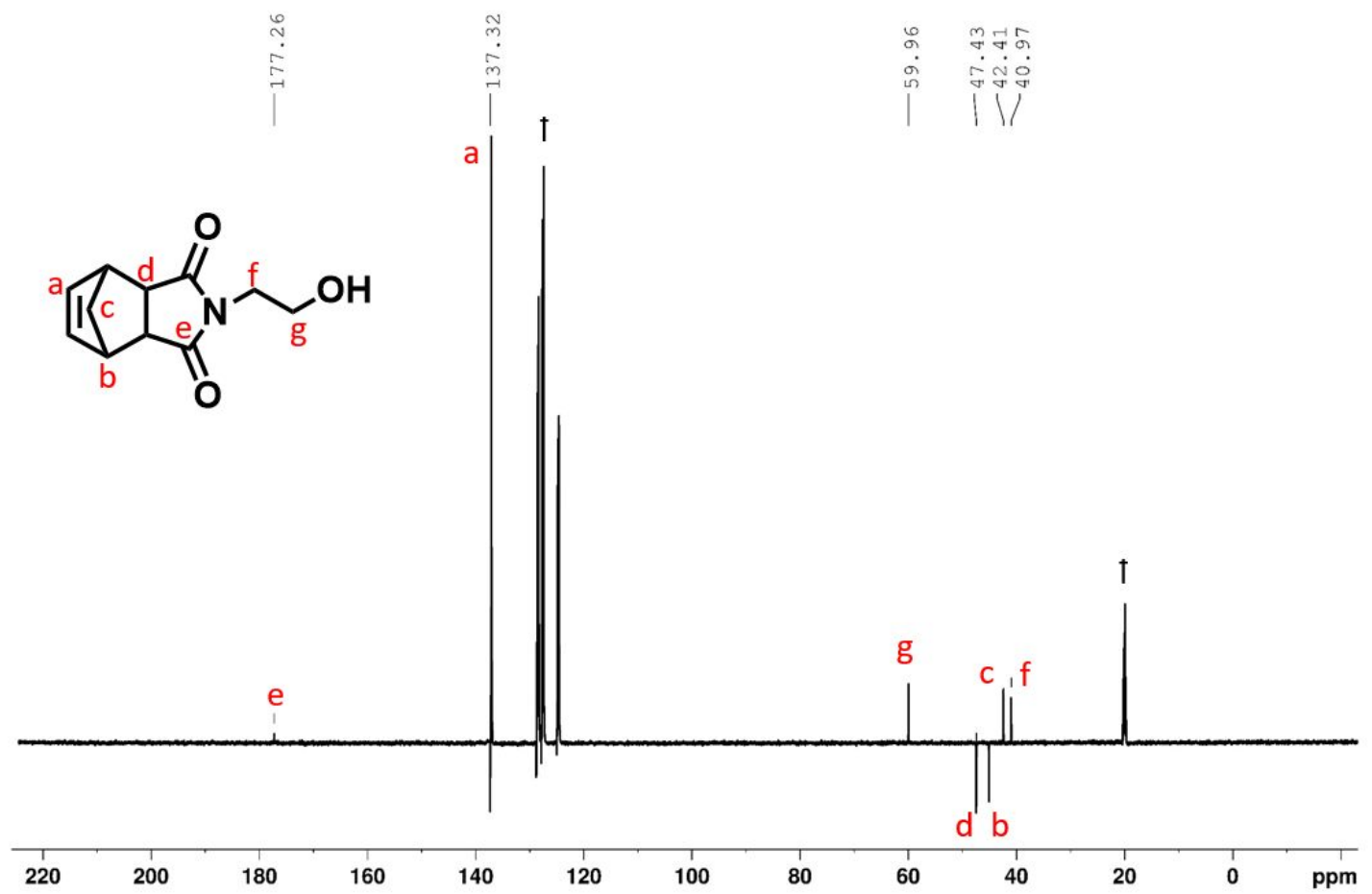

Figure S2. 13C NMR spectrum of HONDC monomer in toluene-d8 at 298K 
<smiles>O=C1C2C3C=CC(C3)C2C(=O)N1CC[OH2+]</smiles>

HONDC<smiles></smiles>

$\overrightarrow{\text { Toluene (dry), } 10 \mathrm{~min}, \mathrm{RT}}$

DTT<smiles>O=C1C2C3C=CC(C3)C2C(=O)N1CCOC1N(c2ccccc2)N=C(c2ccccc2)N1c1ccccc1</smiles>

HONDC-DTT adduct

Scheme S1. Formation of the latent DTT-HONDC adduct

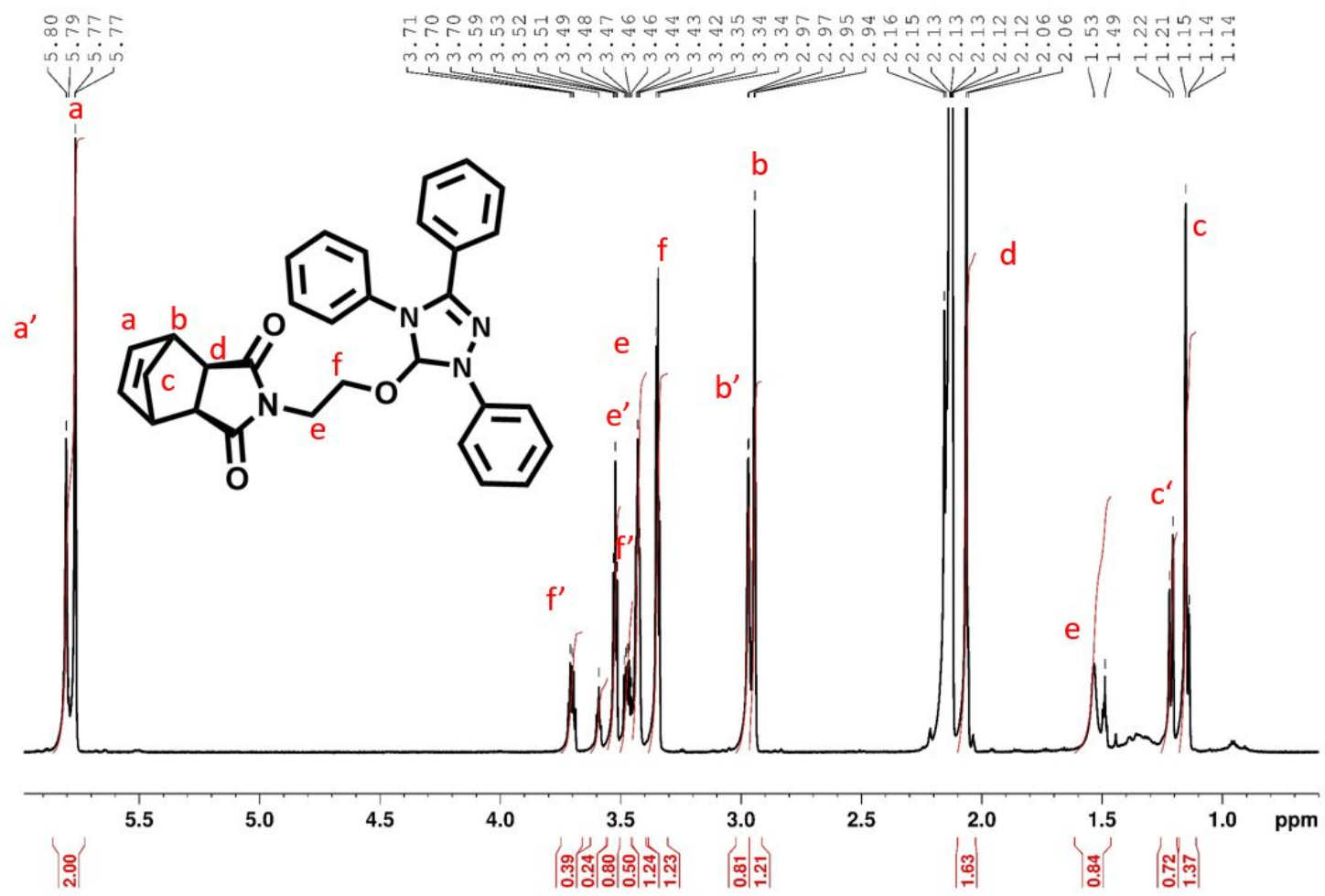

Figure S3.1 HMR spectrum of HONDC monomer as the DTT adduct in toluene-d8 at 298K 


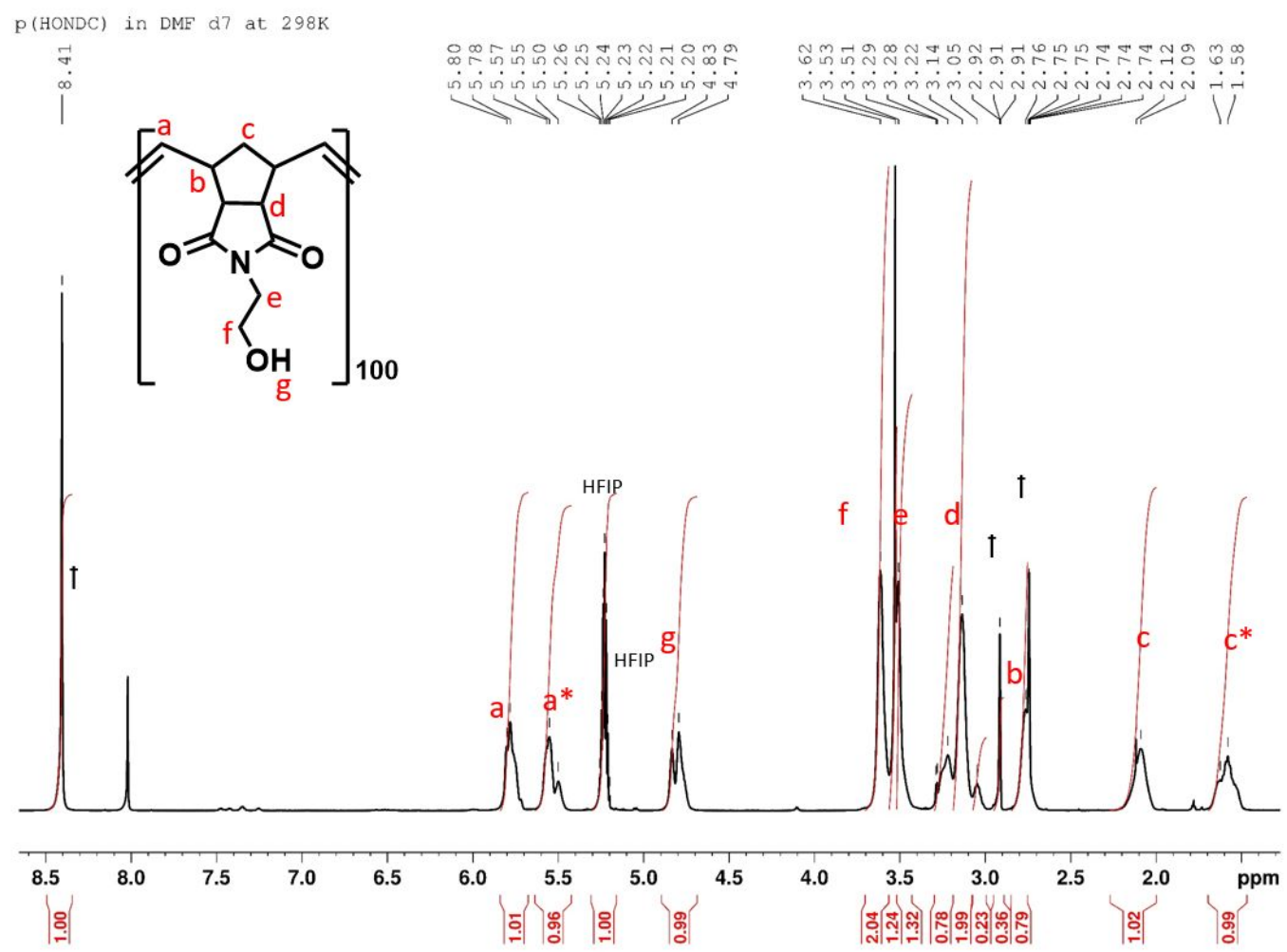

Figure S4. 1H NMR spectrum of poly(HONDC) in DMF-d7with 1\% w/w HFIPat 298K . DP=100

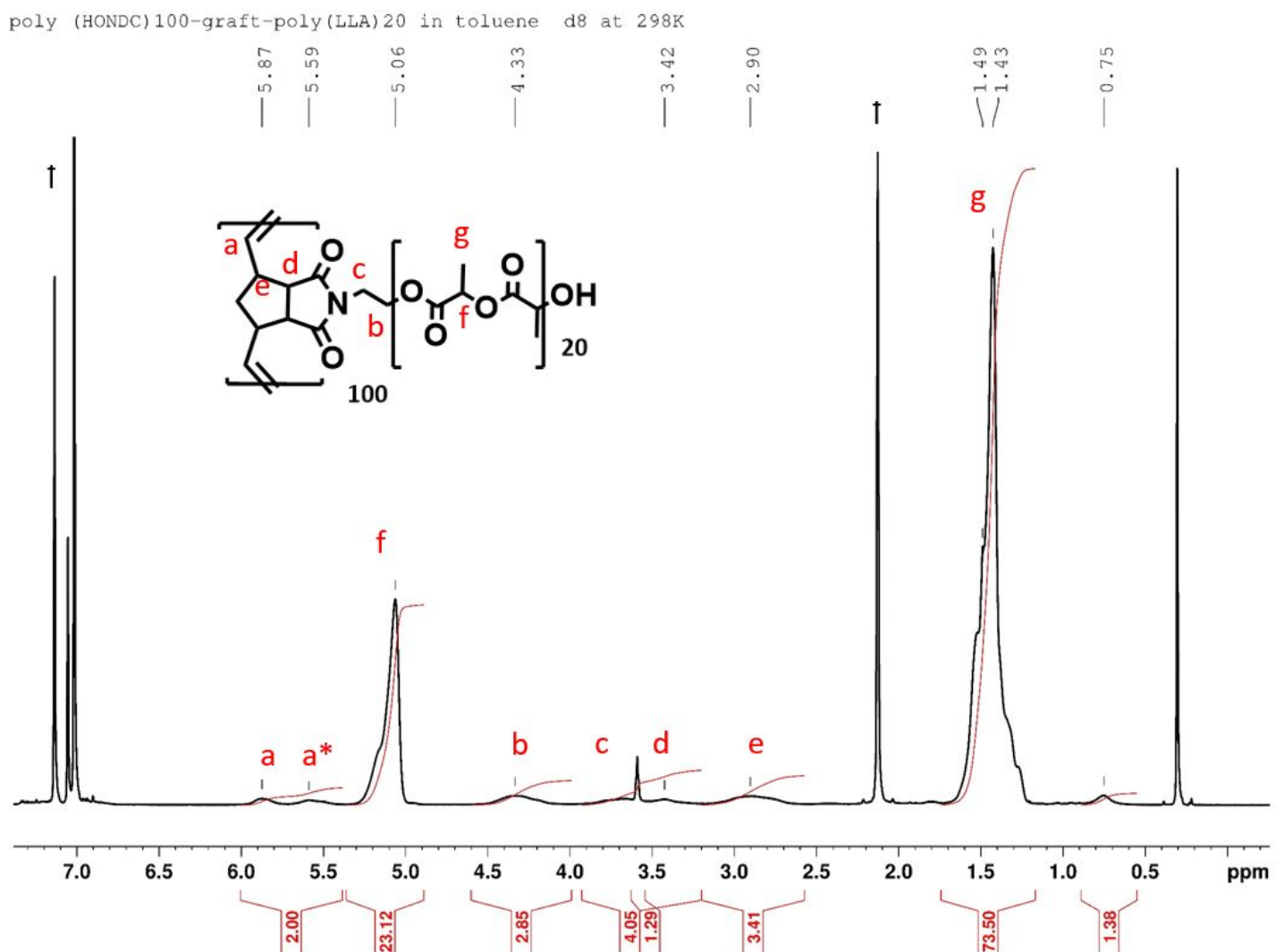

Figure S5. 1H NMR spectrum of bottle brush polymer poly (HONDC)100-gratt-poly(LLA)20 toluene-d8 at 298K. 


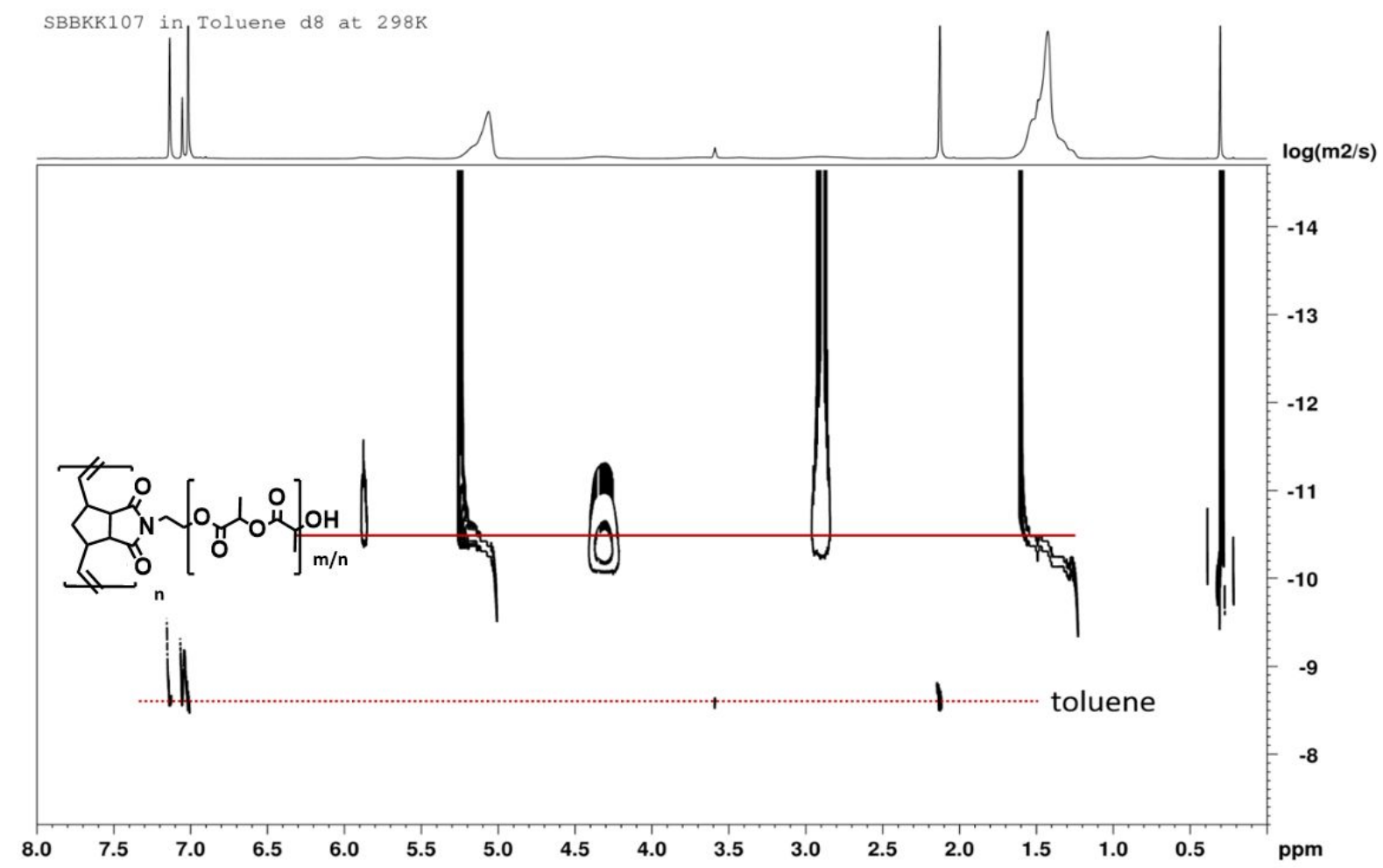

Figure S6. Representative DOSY ${ }^{1} \mathrm{H}$ NMR spectrum of bottlebrush tandem polymerization in toluene. All polymeric signals occur at the same diffusion coefficient and indicate a covalent attachment of the polymer sections. 